\title{
MJN MATERNAL AND NEONATAL BARRIERS OF BREAST-FEEDING: A SYSTEMATIC REVIEW
}

\author{
Ghareeba A. Hasan ${ }^{1}$, Shukir S. Hasan ${ }^{1,2 *}$ \\ ${ }^{I}$ Nursing Department, College of Nursing, Hawler Medical University, Erbil City, Kurdistan region, Iraq \\ ${ }^{2}$ Faculty of Nursing, Nursing Department, Tishik International University, Erbil city, Kurdistan region, Iraq \\ *Corresponding Author’s Email: shukir.hasan@hmu.edu.krd; shukir.hasan@tiu.edu.iq
}

\begin{abstract}
Background and Purpose: Breast milk (mother's milk) is the most natural and valuable nutrient that can be provided easily and comfortably for the infant. Although breast-feeding at the beginning is often done without any problems, the continuation of that, especially the exclusive form of mother's milk, is underestimated in many cases by some factors. Studies aimed at identifying effective factors that can be useful in planning for breastfeeding promotion. Therefore, considering this important issue made the researcher carry out this study with the purpose of identifying the factors affecting the lack of continuity of breastfeeding in mothers based on review of literature and experts standpoints in this regard. Methodology: The present studies under consideration were conducted between 2001 and 2018. These were searched using the exclusive keywords. Mag Iran, SID, Med lib, were examined and data were analyzed by using the meta-analysis method (random effect model). Findings: About 30 articles were identified and examined regarding the effective factors that affected the continuation of successful breastfeeding in infants aged between 0 and 6 months. Finally, a variety of factors influencing the lack of continuous breastfeeding have been classified and discussed in order of maternal, neonatal and environmental factors(in order of effect). Conclusion: In order to investigate the factors effecting breastfeeding continuity by mothers, all nurses must take steps to promote breast-feeding and spread awareness regarding the benefit of breast feeding for children along with recommending avoidance of unnecessary cesarean deliveries, advertisements about the benefits of normal vaginal delivery (NVD) for mother and infant, as well as training for breast-feeding and encouraging it during pregnancy and postpartum, especially in mothers with cesarean deliveries.
\end{abstract}

Keywords: Exclusive Breastfeeding, Continuous Nutrition, Affective Factors in Breastfeeding

\section{INTRODUCTION}

Having healthy children requires the observance of health principles and betterment of their nutrition, especially during infancy (Safari et al., 2018; Sharifirad et al., 2018). Breast milk is the most natural and valuable nutrient that can be provided easily and comfortably for the infant (Allahkarampour et al., 2015; Hasan, 2016). Breast-feeding prevents the death of 7 million children in the world yearly (Victora et al., 2016). So, the probability of mortality due to the gastrointestinal infections, especially diarrheal diseases are 25 times lower among infants fed with mother's milk than those who were fed with dried milk (Rollins et al., 2016). Successful breastfeeding also reduces the incidence of breast cancer and osteoporosis in mother and the risk of diabetes and obesity in the baby and in addition to meeting the emotional needs, it reduces unnecessary costs in family and society (Kramer \& Kakuma, 2012). Throughout the world, especially in Iran, baby-friendly hospitals try to train and promote breastfeeding (Montgomery et al., 2012). This policy and program have been implemented in most countries, and the beginning of breast-feeding have been very successful in most countries and studies. But in our country, on the contrary, however, beginning of breastfeeding is often done without any problems, the continuation of that, especially the exclusive form of mother's milk is underestimated in many cases so the rate of exclusive breastfeeding in the world that is $36 \%$, and this figure in Iran is only $23.1 \%$. The available information indicates that about $80 \%$ of Iranian infants over the age of 15 
months enjoy (possess) the breastfeeding, but this rate is between $50 \%$ and $60 \%$ for those aged between 20 and 23 months (Stuart-Macadam, 2017).

According to literature, nourishment among infant is a complicated decision and influenced by many factors that affect the infant's breastfeeding (Hauck et al., 2011). The full range of breastfeeding varies from one country to another even from one culture to another. Considering this important issue made the researcher carry out this study with the purpose of identifying the factors affecting the lack of continuity of breast-feeding in mothers with a review of researchers and experts standpoints in this regard.

\section{METHODOLOGY}

In this structured review, all domestic studies conducted between 2001 and 2018 by using the keywords "breastfeeding", "mother's milk", "continuation of breastfeeding", "length of breastfeeding continuity", "factors affecting breastfeeding" and "meta-analysis of the country's databases" "breastfeeding", "mother's milk", "continuation of breastfeeding", "length of breastfeeding continuity", "factors affecting breastfeeding" and "metaanalysis of the country's databases". Mag Iran, SID, Med lib, Iran Medex were examined and data were analyzed by using the meta-analysis method (random effect model). The data of the selected articles were collected. After reviewing and collecting all the searched articles; repeated and unrelated articles were excluded. In the next step, the received articles were examined based on the criteria for entering the study which included articles which examined the variety of impressive factors in successful breastfeeding in the first six months of the infants. Moreover, exclusion criteria included data from case reports, posters, conferences, and review articles. All the required ethical issues for the correct use of extracted articles and related rules of publication have been observed.

\section{RESULTS}

After searching the databases and extracting a large number of articles based on the title and abstract, 360 articles were reviewed, in which 293 were excluded due to the reason that the factors in successful breastfeeding had not been studied by them. About 67 articles were reviewed more precisely, in which 37 articles had not examined the impressive factors in successful breastfeeding in infants aged between 0 to 6 months. Finally, 30 articles were entered in this systematic review (PRISMA chart).

\section{0 articles with content of breast-feeding}

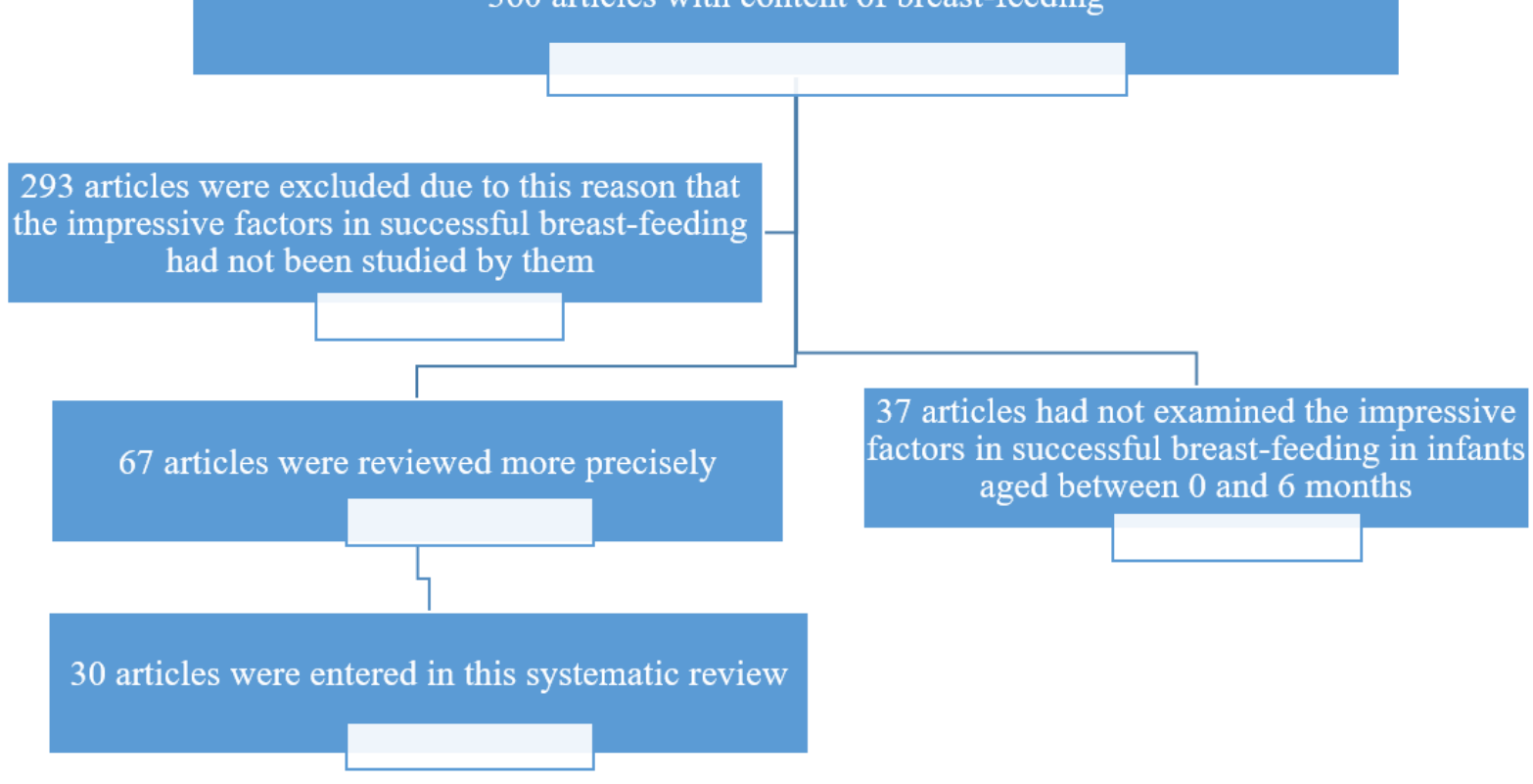

Finally, variety of factors influencing the lack of continuity of successful breastfeeding have been classified and discussed on the basis of maternal, infantile and environmental factors (in order of effect). 
Table 1: Some details of the reviewed studies

\begin{tabular}{|c|c|c|c|c|c|c|}
\hline Author & Title & $\begin{array}{c}\text { Year and } \\
\text { place }\end{array}$ & $\begin{array}{c}\text { Target } \\
\text { population }\end{array}$ & Study type & Outcome criteria & Restrictive factors \\
\hline Pakpour et al., & $\begin{array}{l}\text { Predictive factors } \\
\text { associated with } \\
\text { breastfeeding } \\
\text { initiation and } \\
\text { duration behaviors } \\
\text { of } 6 \text {-months } \\
\text { postpartum mothers } \\
\text { referred to health } \\
\text { centers in the city of } \\
\text { Qazvin based on } \\
\text { theory of planned } \\
\text { behavior } \\
\end{array}$ & $\begin{array}{l}2016 \\
\text { Iran }\end{array}$ & $\begin{array}{l}1445 \text { mothers } \\
\text { with six } \\
\text { months old } \\
\text { child referring } \\
\text { to health } \\
\text { centers }\end{array}$ & $\begin{array}{l}\text { Descriptive-cross } \\
\text { sectional }\end{array}$ & $\begin{array}{l}\text { Questionnaire of factors } \\
\text { associated with the } \\
\text { continuation of } \\
\text { breastfeeding according } \\
\text { to planned behavior } \\
\text { theory }\end{array}$ & $\begin{array}{l}\text { Mother's age, income, } \\
\text { employment, being } \\
\text { primipara and } \\
\text { inappropriate education }\end{array}$ \\
\hline Amirshahi et al., & $\begin{array}{l}\text { Relationship } \\
\text { between duration of } \\
\text { breastfeeding and } \\
\text { some maternal and } \\
\text { neonatal factors }\end{array}$ & $\begin{array}{l}2013 \\
\text { Iran }\end{array}$ & $\begin{array}{l}460 \text { mothers } \\
\text { with premature } \\
\text { neonate }\end{array}$ & $\begin{array}{l}\text { Descriptive- } \\
\text { analytic }\end{array}$ & $\begin{array}{l}\text { Questionnaire of factors } \\
\text { associated with the } \\
\text { continuation of } \\
\text { breastfeeding }\end{array}$ & $\begin{array}{l}\text { Age, labour history, type } \\
\text { of delivery, gender and } \\
\text { birth weigh }\end{array}$ \\
\hline Amini et al., & $\begin{array}{l}\text { The reasons of } \\
\text { breastfeeding } \\
\text { cessation in children } \\
\text { under the age of } 1 \text { in } \\
\text { Women Referring to } \\
\text { Health Centers }\end{array}$ & $\begin{array}{l}2012 \\
\text { Iran }\end{array}$ & $\begin{array}{l}130 \text { mothers } \\
\text { with lack of } \\
\text { breast-feeding } \\
\text { in the case } \\
\text { group and } 149 \\
\text { mothers with } \\
\text { continuous } \\
\text { breast-feeding } \\
\text { in the control } \\
\text { group } \\
\end{array}$ & Case-control & $\begin{array}{l}\text { Questionnaire of factors } \\
\text { associated with the } \\
\text { continuation of } \\
\text { breastfeeding }\end{array}$ & $\begin{array}{l}\text { Distance between } \\
\text { workplace and home, } \\
\text { shortage of breast milk, } \\
\text { shortage of weight gain } \\
\text { and being twins }\end{array}$ \\
\hline Shahri et al., & $\begin{array}{l}\text { Relationship } \\
\text { between maternal } \\
\text { and breastfeeding } \\
\text { patterns and their } \\
\text { continuity }\end{array}$ & $\begin{array}{l}2012 \\
\text { Iran }\end{array}$ & $\begin{array}{l}150 \text { mothers of } \\
\text { children aged } \\
\text { between } 6 \text { to } \\
12 \text { months old } \\
\text { referring to } \\
\text { health centers }\end{array}$ & $\begin{array}{l}\text { Analytic - cross } \\
\text { sectional }\end{array}$ & $\begin{array}{l}\text { Questionnaire of factors } \\
\text { associated with the } \\
\text { continuation of } \\
\text { breastfeeding and } \\
\text { interview }\end{array}$ & $\begin{array}{l}\text { The frequency of breast- } \\
\text { feeding in } 24 \text { hours, type } \\
\text { of delivery, and the } \\
\text { initiation of postpartum } \\
\text { breast-feeding }\end{array}$ \\
\hline Safari et al., & $\begin{array}{l}\text { The effect of mother } \\
\text { and newborn early } \\
\text { skin-to-skin contact } \\
\text { on initiation of } \\
\text { breastfeeding, } \\
\text { newborn } \\
\text { temperature and } \\
\text { duration of third } \\
\text { stage of labor. }\end{array}$ & $\begin{array}{l}\text { Iraq, } \\
2018\end{array}$ & 108 mothers & $\begin{array}{l}\text { Quazi- } \\
\text { expermintal study }\end{array}$ & $\begin{array}{l}\text { Skin-to-skin contact } \\
\text { provides an appropriate } \\
\text { and affordable yet high } \\
\text { quality alternative to } \\
\text { technology. It is easily } \\
\text { implemented, even in } \\
\text { small hospitals of very } \\
\text { low-income countries, } \\
\text { and has the potential to } \\
\text { save newborns' and } \\
\text { mothers' lives. It is } \\
\text { necessary to prioritize } \\
\text { training of health } \\
\text { providers to implement } \\
\text { essential newborn care } \\
\text { including SSC. }\end{array}$ & $\begin{array}{l}\text { Direct skin to skin } \\
\text { contact of baby affects on } \\
\text { body tempreture and } \\
\text { duration of foruth stage } \\
\text { of labor. }\end{array}$ \\
\hline
\end{tabular}

\section{DISCUSSION}

According to what have mentioned, a variety of factors affecting the lack of continuous successful breastfeeding have been classified and discussed based on maternal, infantile and environmental factors (in order of effect). The articles in relation to the mentioned factors were analyzed. The table below shows some details about the mentioned studies (Table 1). 


\section{Maternal Factors}

The maternal factors associated with the lack of breast-feeding continuation of breastfeeding analyzed in the studies are as follows (Talebi et al., 2005; Almasi et al., 2006; Ekhtiari et al., 2008; Shiva et al., 2008; Hajikazemi et al., 2009; Khoshtarash et al., 2010; Azimi et al., 2010; Hamidi et al., 2011; Raisi Dehkordi et al., 2012; Amini et al., 2012; Shahri et al., 2012; Amirshahi et al., 2013; Mokhtary et al., 2014; Gafari et al., 2014; Ansari Jaberi et al., 2015; Heidari et al., 2016; Pakpour et al., 2016).

Mother's negative attitude towards breastfeeding, previous unsuccessful breastfeeding, short interval between two offspring, family disputes, mother's psychological status, a separation between mother and her child, sexual dysfunction due to lactation such as milk secretion during intercourse or fatigue caused by breast-feeding, lack of breast-feeding during the night, insufficient milk in mother's breasts, mother's belief that a short period of breast-feeding will suffice, unintended pregnancy, breast diseases such as fissure, abscess and ulcer, the use of inappropriate methods of contraception, such as hybrid methods that negatively affect the breastfeeding process, inexperienced primiparas, smooth breast or nipple deformity, getting pregnant again, early onset of supplemental nutrition. All these causes the child to be reluctant towards breast milk, fear of breast deformity and slimming and frequent use of pacifier.

The demographic factors affecting the successful breast-feeding include education, mother's occupation, weight and delivery type. The effect of the aforementioned factors is that mothers with higher education and those who are working would terminate the exclusive breastfeeding earlier. According to the reviewed studies, about $83 \%$ of mothers with physical occupations have used dried milk 1-6 times a day. Overweight mothers opt for cesarean deliveray more, therefore they have terminat breastfeeding indirectly.

The type of delivery is one of the significant maternal factors in successful breastfeeding process. According to the studies, mothers with cesarean section was more likely to be unsuccessful in nursing their infants. Regarding the mechanism of secretion of oxytocin and dilation of the female genital tract during labour and the effect of the pain on the secretion of this hormone, it can be stated that in normal vaginal delivery (NVD), in comparison with cesarean section, especially in elective cases where the mother are unable to tolerate the labor pain, oxytocin secretion is more; also, anaesthetics and analgesics that are used in cesarean section are effective on the secretion of oxytocin. So, it has been shown that morphine sulfate stops releasing the breastmilk.

One of the variables that are constantly associated with the positive results of breast-feeding are self assured nursing of the mother, in other words, selfefficacy of breast-feeding. Low assurance of breastfeeding can be associated with the mothers' perception of inadequate milk supply, which results in the use of formula and shortage of nursing continuity. It seems that the mothers' unawareness of the lactation and its relation with breast milk consumption by the infant, as well as the mothers' concern about the use of contraceptive pills were the most frequent reason for the lack of breastfeeding continuity. Therefore, maternal periodic assessment should be emphasized and recommended for proper and correct nursing and the elimination of possible problems, especially during the first six months of infant's life.

Also, for further studies, it is recommended that mothers' performance and self-efficacy in exclusive breastfeeding and its continuation should be examined. The effect of psychological factors on mothers' nursing behaviours has been studied in different literatures. The consequences of these researches indicate that there is a significant relationship between maternal depression and patterns of emotional regulation and their social functions. So mothers with mental disorders, did not respond adequately to the infant's needs and do not have enough energy to take care of their child; also, they show less positive interactions with their child and show less sensitivity when they are interacting with them.

\section{Neonatal Factors}

In the reviewed studies, the neonatal factors affecting the continuation of breastfeeding is related to cases such as crying and the restlessness of the child, polytocous, no sucking of mother's breasts, pediatric diseases such as cleft lip or palate or reflux and gastroenteritis, child incompatibility with breast milk, birth order and birth weight in sequence (Barak et al., 2005; Esfarjani et al., 2008; Abasikakruodi et al., 2008; Ekhtiari et al., 2008; Khoshnevisasl et al., 2010; Mirmohammadali et al., 2011; Noohi et al., 2011; Tarvij et al., 2014; Sakkaki et al., 2013; Hasan, 2016).

The birth order effect breastfeeding continuity by the mother. Ascending in birth order increases the 
possibility of breastfeeding continuity, which is due to the increase in self-confidence of mother in nursing. Thus the first-born children are exposed to the possibility of not receiving the breast milk exclusively. Also, the birth weight is another important factor in this regard. So, the newborns and the infants who are underweighted, in comparison with their peers, receive other nutritional supplements that affect successful breast-feeding, because of their more special cares.

\section{Environmental Factors}

According to the studies, some of the factors affecting the lack of successful breastfeeding continuity was not associated with maternal and neonatal factors. So they were classified into environmental factors which include inappropriate economic situation of the family, lack of adequate support by government and healthcare workers, access to the dried milk in well-off families, physician's advice, lack of support by relatives and poor culture (Emami et al., 2007; Mojalli et al., 2010; Mohammadpour et al., 2015; Akaberian et al., 2015; Hasan, 2016; Arshad et al., 2017).

It is evedent that the reasons identified from the data regarding the start and stop of breastfeeding are the factors like advice about breastfeeding that was useful or not useful, and cultural issues related to breastfeeding that were perceived to be unique among African Americans (Lewallen \& Street, 2010). Poor culture and lack of educational support by health centres seem to be the most dominant factors in this classification. Baby's nourishment should be continued by cow's milk. Also, the physicians are not familiar with the educational materials of the health centres, the lack of coordination between physicians and healthcare centres, the private sector's performance and the public (state) sector instructions, the lack of employees information and the inappropriate behaviour of the staff towards the mothers, heavy workload for the health staff are some of the other factors responsible for the discontinuation of breast feeding among mothers. Healthcare staff does devote enough time time to consult the mothers. Therefore lack of educational support by health centres is an important factors that lead to the discontinuity of breastfeeding by mothers.

\section{CONCLUSION}

Having healthy children requires the observance of health principles and betterment of their nutrition, especially during infancy. According to the reviewed studies it is evident that the onset of nutrition is often the mother's responsibility, but the continuation of breastfeeding, especially the exclusive breast feeding in many cases, is influenced by maternal, neonatal and environmental factors. The amount of exclusive breastfeeding and its controlling factors in the current study indicate that more attention is required for conducting further studies in this regard. Attitude and awareness of mother's and health staff's and their continuous education process about nutrition is necessary. In order to solve this problem nurses must take steps to promote breast-feeding for the benefit of the children from this great blessing. Unnecessary cesarean deliveries must be avoided and more advertisements about the benefits of normal vaginal delivery (NVD) for mother and infant is required. As well as training of mothers regarding breast-feeding and encouraging it during pregnancy and postpartum, especially in mothers with cesarean deliveries is essential.

\section{Conflict of Interests}

The authors declare that they have no conflict of interest.

\section{ACKNOWLEDGEMENT}

The authors are thankful to the institutional authority for completion of the work.

\section{REFERENCES}

Abasikakruodi, M., Rahbar, A., Yaghoobi, A. \& Eskandari, S. (2008). Breastfeeding: A Vital Emergency in Crisis. Journal of Holistic Nursing and Midwifery, 18(2), pp 51-53.

Akaberian, S., Jamand, T., Zahmatkeshan, N., Bagherzadeh, R., Mirzaei, K., Gharibi, T., Yazdankhah, M., Kamali, F., Khoramroodi, R. \& Pouladi, S. (2015). Comparing the Effectiveness of Multimedia and Routine Educations on Exclusive Breast Feeding in Children Less than 6 Months In Health Centers of Bushehr City. Iranian South Medical Journal, 17(6), pp 1252-1260.

Allahkarampour, F., Pishva, N. \& Keshavarzi, S. (2015). A Survey of The Impact of Proper Breastfeeding Education on Blood Sugar Levels of Healthy Term Infants In The Public Hospital of Shahid Rajai In Gachsaran In 2013. Journal of Clinical Nursing and Midwifery, 4(3), pp 12-22. 
Almasi, H., Saberi, H. \& Moravveji, S.A. (2010). The Pattern of Exclusive Breast Feeding In Neonates under Healthcares in Health Centers of Kashan City During 2006. Feyz, 14(2), pp 163-168.

Amini, R., Mohammadi, N., Omid, A., Khodavisi, M., Borzo, R. \& Moradi, F. (2012). Causes of Lactation in Children under 1 year of age in Women Referring to Health Centers 20 Hamedan. Journal of Nursing and Midwifery (Nasim Danesh), 20(2), pp 58-64.

Amirshahi, M., Shiri, S., Salehin, S. \& Mohamad Rezaei, Z. (2013). A Study on the Relationship Between Duration of Breastfeeding and Some Maternal and Neonatal Factors. Journal of Urmia Nursing and Midwifery Faculty, 11(5), pp 1-5.

Ansari Jaberi, A., Negahban Bonabi, T., Alahtavakoli, M. \& Kazemi, M. (2015). Maternal Affectivity and their Infants Feeding Pattern among Referrers to Health Care Centers in Rafsanjan in 2011. Journal of Rafsanjan University of Medical Sciences, 14(1), pp 47-56.

Arshad, S.M., Khani-Jeihooni, A., Moradi, Z., Kouhpayeh, S.A., Kashfi, S.M. \& Dehghan, A. (2017). Effect of Theory of Planned Behavior-Based Educational Intervention on Breastfeeding Behavior in Pregnant Women In Fasa City, Iran. Journal of Education and Community Health, 4(2), pp 55-63.

Azimi, N., Akhavan Karbasi, M. \& Jafari, A. (2010). Quantitative Comparison of Oral Fungal Colonies in the BreastFeeding and Bottle-Feeding Infants. Journal of Dental Medicine, 23(3), pp 175-182.

Barak, M., Amani, F., Mirza Rahimi, M., Abbasgholizadeh, N. \& Hamid Kholgh, A.R. (2005). Evaluating Mothers' Knowledge About Infant Proper Nutrition in Hir Health Center, 2001. Journal of Ardabil University of Medical Sciences, 5(1), pp 26-29.

Ekhtiari, A. \& Emami, P. (2008). Comparison of Success Rates in Breastfeeding after Vaginal Delivery and Cesarean Section. Medical Sciences, 18(1), pp 51-54.

Emami, P. \& Aref, S. (2007). Maternal Knowledge, Attitude and Perception About. Medical Sciences, 17(3), pp 165169.

Esfarjani, F., Salarkia, N., Roustaee, R. \& Abadi, A. (2008). Anthropometric Assessment of the Nutritional Status of Under-5-Year-Old Children in Mother-Headed Households Under Coverage of the Imam Khomeini Relief Foundation of Tehran and Factors Related to it, 2005. Iranian Journal of Nutrition Sciences \& Food Technology, 2(4), pp 41-48.

Gafari Asl, M., Fadakar Sogheh, R., Ghavi, A. \& Ahmad Shear Bafi, M. (2014). Related Factors to Continued Breastfeeding in Infants. Journal of Holistic Nursing and Midwifery, 24(2), pp 1-8.

Hajikazemi, E., Allahgholi, L., Jamshidimanesh, M. \& Hosseini, F. (2009). The Relationship between Body Mass Index Before Pregnancy and Duration of Breast Feeding. Iran Journal of Nursing, 22(57), pp 9-18.

Hamidi, M., Khoshdel, A., Khadivi, R., Deris, F., Salehi-Fard, A., Parvin, N. \& Malekahmadi, M. (2011). The Causes of Formula Milk Consumption in the Infants Under 1 Year Old In Charmahalva Bakhtiari Provins Iran, 2007. Journal of Shahrekord University of Medical Sciences, 13(3), pp 77-83.

Hasan, S.S. (2016). Factors influence on Primigravida's knowledge regarding exclusive breastfeeding benefits in Maternity Teaching Hospital: Erbil city - Kurdistan region - Iraq. Zanco Journal of Medical Sciences, 20(3), pp 1505-12.

Hauck, F.R., Thompson, J.M., Tanabe, K.O. \& Moon, R.Y. \& Vennemann, M.M. (2011). Breastfeeding and Reduced Risk of Sudden Infant Death Syndrome: A Meta-Analysis. Pediatrics, 28(1), pp 103-110.

Heidari, B., Etemadifar, S. \& Raeisi, M. (2016). The Effectiveness of a Supportive Educative Program on Mothers' Knowledge and Behavior About Breast Feeding in Health Care Centers of Shahrekord City 2012. Journal of Clinical Nursing and Midwifery, 5(1), pp 67-75. 
Khoshnevisasl, P., Sadeghzadeh, M., Mazloomzadeh, S., Koosha, A. \& Dariabari, S. (2010). Maternal Knowledge about Nutritional Status of 6 to 12-Month-Old Infants in the Community Oriented Medical Education of Zanjan University of Medical Sciences. Journal of Advances in Medical and Biomedical Research, 18(71), pp 61-69.

Khoshtarash, M., Ghanbari, A., Yeganeh, M., Kazemnezhad, E. \& Rezasoltani, P. (2010). Survey the Effect of Foot Reflexology on Pain and Physiological Parameters after Cesarean Section in Patients Referring to Alzahra Educational Center in Rasht. Journal of Holistic Nursing and Midwifery, 20(2), pp 27-33.

Kramer, M.S. \& Kakuma, R. (2012) Optimal Duration of Exclusive Breastfeeding. Cochrane Database of Systematic Reviews, 8, CD003517.

Lewallen, L.P. \& Street, D.J. (2010). Initiating and Sustaining Breastfeeding in African American Women. Journal of Obstetric, Gynecologic \& Neonatal Nursing, 39(6), pp 667-674.

Mirmohammadali, M., Golian Tehrani, S., Kazemnejad, A., Hosseini Baharanchi, F.S., Minaee, B., Bekhradi, R. \& Dehkordi, Z.R. (2011). A Comparative Study of the Effect of Massage with Sunflower oil or Sesame Oil on Infants' Crying and Sleep Times: A Randomized Clinical Trial. Hayat, 17(3), pp 80-90.

Mohammadpour, A., Khajavi, A., Moshki, M., Zarei, M., Hashemizadeh, H., Farzamfar, S. \& Namnik F. (2015). Level of Malnutrition and Failure to Thrive in 1-18 Month Old Infants. The Horizon of Medical Sciences, 21(4), pp 1-6.

Mojalli, M., Basiri Moghadam, M. \& Shamshiri, M. (2010). Effectiveness of Instructional Environment and Related Factors on Breastfeeding Function of Mothers. The Horizon of Medical Sciences, 16(1), pp 59-64.

Mokhtary, L., Khorami Marekani, A. \& Habibpoor, Z. (2014). The Effect of Face to Face Education and Pamphlet Giving on Knowledge of Mothers about Breast Feeding. Journal of Urmia Nursing and Midwifery Faculty, 12(9), pp 825-832.

Montgomery, A., Hale, T.W. \& Academy of Breastfeeding Medicine (2012). ABM clinical protocol \#15: analgesia and anesthesia for the breastfeeding mother, revised 2012. Breastfeeding Medicine, 7(6), pp 547-53.

Noohi, E., Soltani Nejad, A. \& Safi Zadeh, H. (2008). Feeding Patterns and Colicky Infants. Journal of Qualitative Research in Health Sciences, 11(1 and 2), pp 51-58.

Pakpour, A., Alijanzadeh, M., Pouresmaeil, M., Taherkhani, F., Mohammadgholiha, R. \& Jozi, N. (2016). Predictive Factors Associated with Breastfeeding Initiation and Duration Behaviors of 6-Months Postpartum Mothers Referred to Health Centers in the City of Qazvin Based on Theory of Planned Behavior. Iranian Journal of Health Education and Health Promotion, 4(1).

Raisi, Z.D., Raei, M., Ghassab, M.S., Raisi Dehkordi, S.A.R. \& Mirmohammadali, M. (2012). Effect of Telephone Counseling on Continuity and Duration of Breastfeeding among Primiparus Women. Hayat, 18(2), pp 57-65.

Rollins, N.C., Bhandari, N., Hajeebhoy, N., Horton, S., Lutter, C.K., Martines, J.C., Piwoz, E.G., Richter, L.M., Victora, C.G. \& The Lancet Breastfeeding Series Group (2016). Why Invest, and What it Will Take to Improve Breastfeeding Practices? The Lancet, 387(10017), pp 491-504.

Safari, K., Aziz, A.S., Hasan, S.S. \& Moghaddam-Banaem, L. (2018). The effect of mother and newborn early skin-toskin contact on initiation of breastfeeding, newborn temperature and duration of third stage of labor. International Breastfeeding Journal, 13(1), pp 1-8.

Sakkaki, M. \& Khairkhah, M. (2013). Promotion of Exclusive Breastfeeding: Teaching Good Positioning and Support from Fathers and Families. Journal of Urmia Nursing and Midwifery Faculty, 10(6).

Shahri, P., Balooti, T., Sa'atati, N. \& Haghighizadeh, M.H. (2012). Relationship between maternal and breastfeeding patterns and their continuity. Footnote, 11(6), pp 893-899.

Sharifirad, G., Shahnazi, H., Sedighi, E. \& Mahaki, B. (2018). The Effect of Supporter Presence in Education Sessions of Breastfeeding on Knowledge, Attitude and Behavior of Nulliparous Women. Journal of Health, 9, pp 45-61. 
Shiva, F., Sallemi, F. \& Fakhteh Yavari, S.H. (2008). The Effect of Pacifier Use on Breast-Feeding Duration. Research in Medicine, 32(4), pp 261-265.

Stuart-Macadam, P. (2017). Breastfeeding in Prehistory. Inbreastfeeding, pp 75-100. UK: Routledge.

Talebi, M., Sarraf Shirazi, A. \& Ismaili, H. (2005). The Relationship Between Diet and Oral Hygiene Status and Gingival Health In Preschool Children in Private Kindergartens in Mashhad. Journal of Mashhad Dental School, 29(3,4), pp 223-134.

Tarvij, S.E., Nassirian, H. \& Danesh, H.A. (2014). Comparing Growth Indices between Exclusive Breastfed Infants $\leq 6$ Months and Growth Standards of National Center Health Statistics in Iran. Medical Sciences, 23(4), pp 262-268.

Victora, C.G., Bahl, R., Barros, A.J., França, G.V., Horton, S., Krasevec, J., Murch, S., Sankar, M.J., Walker, N., Rollins, N.C. \& Lancet Breastfeeding Series Group. (2016). Breastfeeding In the $21^{\text {st }}$ Century: Epidemiology, Mechanisms, and Lifelong Effect. The Lancet, 387(10017), pp 475-90. 